\title{
Commentary
}

\section{My 20 Years at CORESTA}

\author{
François Jacob, former Secretary General of CORESTA
}

\begin{abstract}
May I first thank the Editorial Board of this Journal for having invited me to write a short article on my experience as CORESTA Secretary General, a position I held from mid-1989 to the end of 2009 - that is more than 2 decades. CORESTA (Centre de Coopération pour les Recherches Scientifiques Relatives au Tabac) ${ }^{1}$ was founded in 1956 in Paris to promote international cooperation in scientific research on tobacco. Today, it has developed into a global organization with 180 members from 44 countries.

I was the last Secretary generously supported by SEITA, at their cost, out of their stock of executives, and the first to take this job without experience in research and development. However, my former assignments in manufacturing, leaf buying and export sales helped me considerably in establishing good relationships with the multinational group of CORESTA experts and executives. I shall briefly mention that at that time the internal organisation of the Secretariat and Board was in many ways not up-to-date. For instance, the Board of twelve included six "entitled" members, mainly State Monopolies, which prevented companies most active in the actual work from being officially represented. A series of changes of the Statutes happened from 1992 to 2000, resulting in a more representative and active Board. Until 2000, all documents were bilingual French-English, including the database with literature information distributed on a CD since 1996. English was made the sole working language in 2000, and the printed Bulletin was discontinued. The CORESTA offices became separated from SEITA's head office in 2000, and finally the Secretary General was on CORESTA's payroll as of 2001.
\end{abstract}

On the other hand, the scientific work had been well organised from the early years of CORESTA, with four Study Groups: Agronomy and Phytopathology (AP) on the "plant" side, Smoke and Technology (ST) on the "product" side. AP and ST had different sets of participants and separate annual meetings in odd years, while all groups participated in the full Congresses held in even years. In spite of some requests for change, the structure was maintained up to nowadays, with the Smoke Study Group renamed to Smoke Science Study Group and the Technology Study Group to Product Technology Study Group (2001).

Within this general frame, many CORESTA's procedures and rules were modified to ensure better use of resources and better reactivity to the needs of the tobacco sector. Task Forces and Sub-Groups are set up within the Study Groups to address a specific issue, which may be the development of a new analytical method for a specific compound, the monitoring of a tobacco disease or the ways to reduce agrochemical residues in tobacco. Task Forces engage in work for a limited time span, whereas SubGroups are set for longer duration.

As research becomes more sophisticated it tends to focus on highly specialised domains, and experts in a field may be quite unaware of developments in other sectors. The necessity to establish links between plant and product people was clearly perceived even before my time. In the early 1990s, it was decided to have yearly "intergroup papers" at meetings and Congresses, i.e. the Reading Committee would select an Agro-Phyto paper of particular and general interest for presentation to the Smoke-Techno meeting and the other way around. This proved rather popular and was maintained since. Of course, this exchange is going on only for the time of a conference.

Another strong link between people of different background was created by forming ACAC, the Agro-Chemicals Advisory Committee founded in 1990 to reflect on agrochemicals issues and suggest work items for CORESTA. This committee is composed of people with expertise in various domains from leaf growing to toxicology and analytical chemistry and has done very useful work.

What has become very clear in past years is the everincreasing weight of regulation on CORESTA work. It never was unimportant: the major ongoing work in the late 1980s and early 1990s was the harmonisation of smoking methods. Although it was a legitimate topic per se it was 
made pressing by the need for harmonisation within the European Union due to upcoming regulations on 'tar' and nicotine ceilings. Looking at the present list of Task Forces and Sub-Groups only a few are free from regulatory considerations, and the whole purpose of CORESTA is actually shifting to working on regulations, desirably in cooperation with regulators.

Consequently, CORESTA Recommended Methods were developed, in a cooperative approach, for a broad range of physical and chemical parameters (relevant for quality assurance and product characterization) and several of these methods have formed the basis for the establishment of standard methods by the International Organization for Standardization (ISO).

The theme of the 2010 Congress in Edinburgh was "Promoting the Scientific Basis for Tobacco Product Regulation", and this would have been unconceivable only ten years earlier (the theme for 2000 was "Challenging the New Millennium"). Needless to say, this also implies to engage in research relevant for the human consumer, such as smoking behaviour, uptake of smoke components or the assessment of toxicological effects, a step that CORESTA only took after long discussions and some reluctance to enter these fields.

It should be emphasized that the opening-up of CORESTA to regulatory needs and aspects of product use by consumers has not only impressively widened the range of work items for Task Forces and Sub-groups but also attracted many new members from the surroundings of the tobacco industry, such as regulatory bodies, analytical (contract) laboratories and chemical companies. Therefore, CORESTA has turned, within the last ten years or so, into a much more open and interactive organisation.

Not surprisingly, some working groups are "better born" than others. If the topic is high on the priority list, if practical results are to be expected leading to savings, if the objectives are well defined and do not conflict with proprietary issues, then the attendance is high and qualified and sufficient resources are provided for by participating members. This is why in time more attention was given to the prospective "success" of a working group and slow working groups were disbanded.

During my time in office I attended a large number of meetings and listened to an even larger number of presentations. As a layman, I have to admit that in many cases I hardly understood what was being said but I also learned a lot, in particular with respect to the variability of measurements.

It should be part of the basic education of every citizen everywhere that most measurements have nothing to do with measuring the kitchen table with a measuring tape. Sampling issues, method variability, repeatability and reproducibility are concepts probably ignored by most media, politicians and citizens worldwide, and I plead guilty to having discovered these aspects very late.

It was a surprise to me that proficiency tests for agrochemical residues or nicotine in body fluids, involving first-class laboratories fully equipped and with qualified personnel, initially revealed a very large spread of results, not speaking of so-called false negatives or positives.

The complexity of real-life measurements is largely ignored and one can only become extremely sceptical of numbers given to the general public by the media, governments, militant groups and others when usually no mention of sampling or variability is ever made. More troubling is the fact that there are no validated methods for a number of legally required measurements, and this goes well beyond tobacco regulation. So-called "developed" societies are producing more regulations than they can fully adopt and enforce, leading to ever more layers of bureaucracy with no real benefits.

I feel privileged to have spent the best years of my career enjoying contacts and exchanges with a very nice crowd: the tobacco scientists. 